\title{
Control of Rhizoctonia solani in Sugar Beet and Effect of Fungicide Application and Plant Cultivar on Inoculum Potential in the Soil
}

Anika Bartholomäus, Institute of Sugar Beet Research, Holtenser Landstr. 77, D-37079 Göttingen, Germany; Stefan Mittler, Syngenta Agro GmbH, Am Technologiepark 1-5, D-63477 Maintal, Germany; and Bernward Märländer and Mark Varrelmann, Institute of Sugar Beet Research, Holtenser Landstr. 77, D-37079 Göttingen, Germany

\begin{abstract}
Rhizoctonia solani (AG 2-2 IIIB) is the causal agent of Rhizoctonia root and crown rot, a disease that causes severe economic problems in sugar beet growing areas worldwide. In the United States, azoxystrobin is the most important active ingredient for fungicidal control of $R$. solani in sugar beet, showing efficacy superior to other substances. First reports on resistance development in $R$. solani, however, underline the importance of a careful fungicide resistance management. For this reason, the efficacy of a new fungicide mixture of azoxystrobin and difenoconazole was compared with a fungicide containing only azoxystrobin. Field trials were carried out under natural infection conditions as well as with inoculation in the years 2012, 2013, and 2014. Evaluation of the disease severity and the obtained white sugar yield of different sugar beet

cultivars demonstrated that both fungicide treatments possess a similar efficacy, reducing the diseased beet surface by up to $78 \%$ and preventing yield losses. Additionally, a real-time PCR assay, based on DNA extracts from representative soil samples $(250 \mathrm{~g})$, was used to directly determine the effect of chemical treatment and plant cultivar on the soil-borne inoculum. Fungicide application significantly reduced the concentration of soil-borne inoculum by up to $97 \%$. Furthermore, the results demonstrated that the cultivation of a susceptible cultivar significantly increases the concentration of $R$. solani in the soil by a factor of 200. In conclusion, the study implies that only a combination of resistant cultivar and fungicide application can prevent an accumulation of $R$. solani inoculum under conducive conditions in infested fields.
\end{abstract}

Rhizoctonia solani Kühn (teleomorph: Thanatephorus cucumeris [Frank] Donk) is a ubiquitous soil-borne basidiomycete, which causes disease in many economically important crops, including rice, soybean, potato, corn, and sugar beet (Anderson 1982). Based on vegetative incompatibility, the species is divided into different anastomosis groups (AGs), which are further subdivided into intraspecific groups according to characteristics like host range or biochemical properties (Arakawa and Inagaki 2014; Carling et al. 2002). Different AGs possess distinct host crop specificities, but the host range can vary widely and many crops can be infected by multiple AGs (Carling et al. 2002).

The AGs 2-2 IIIB, AG 2-2 IV, and AG 4 are the causal agents of Rhizoctonia root and crown rot and seedling damping-off in sugar beet (Beta vulgaris L. ssp. vulgaris), resulting in severe yield losses worldwide. Apart from some regions in Idaho, where AG-4 is the dominant species, the AG 2-2 IIIB is the most important anastomosis group in the United States (Strausbaugh et al. 2011). In Europe, more than 36,000 ha are affected by Rhizoctonia root and crown rot caused by AG 2-2 IIIB each year (Garcia et al. 2001). In Germany and other countries of the E.U., the control of Rhizoctonia root and crown rot is restricted to agronomic measures like crop rotation, plant residue management, and tillage practices (Buhre et al. 2009). These measures are able to decrease disease severity, but provide only incomplete control, as $R$. solani has a wide host range and is able to survive in the soil for long time periods (Anees et al. 2010; Buhre et al. 2009; Rush and Winter 1990). Cultivation of resistant cultivars is therefore the primary component of the $R$. solani control in the E.U. (Buddemeyer and Märländer 2005). However, the quantitative resistance of the available cultivars results in insufficient disease control and additionally is connected to yield penalty under nondiseased conditions (Buddemeyer and Märländer 2005; Panella and Ruppel 1996). In contrast to other countries affected by Rhizoctonia root and crown rot, no fungicides are yet registered to control this disease in the E.U. In the U.S., the active ingredient azoxystrobin (AZ),

Corresponding author: Mark Varrelmann, E-mail: Varrelmann@ifz-goettingen.de Accepted for publication 21 February 2017.

(c) 2017 The American Phytopathological Society formulated as Quadris (Syngenta, Greensboro, NC), was labeled in 1999 for foliar application in the four- to eight-leaf stage to control $R$. solani in sugar beet and the label was extended in 2000 for, e.g., in-furrow application (Kiewnick et al. 2001). Since then, various studies have been published that demonstrate the excellent efficacy of this active ingredient for the control of Rhizoctonia root and crown rot (Barnett et al. 2011; Kiewnick et al. 2001; Stump et al. 2002, 2004). In addition, other fungicides have been developed like Proline (prothioconazole, Bayer Crop Science, Research Triangle Park, NC) or Headline (pyraclostrobin, BASF, Research Triangle Park, NC), which possess the ability to reduce Rhizoctonia root and crown rot, but the application dosage required for a protection level similar to that achieved by AZ is considerably higher (Bolton et al. 2010; Liu and Khan 2016a). Today, AZ is considered the "industry standard" for controlling $R$. solani in sugar beet in the U.S., being used either for foliar or in-furrow application (Liu and Khan 2016b).

AZ belongs to the group of $\mathrm{Q}_{\mathrm{o}} \mathrm{I}$ fungicides, which bind at the $\mathrm{Q}_{\mathrm{o}}$-site of the cytochrome $\mathrm{b}$ and thus block the electron transfer, leading to the inhibition of mitochondrial respiration (Bartlett et al. 2002). Since a single amino acid substitution may result in resistance to this group of fungicides, the general risk of resistance development is considered to be high (Fernández-Ortuño et al. 2010). Even though $R$. solani is considered a fungus with low risk of resistance development (Brent and Hollomon 2007), AZ-resistant isolates have been described in rice and potato (Djébali et al. 2014; Olaya et al. 2012). So far, no resistant isolates have been detected in sugar beet, but the report of an AG 2-2 IIIB isolate with resistance toward AZ derived from bent grass (Blazier and Conway 2004) underlines the need of alternative active ingredients for durable fungicidal control of $R$. solani in sugar beet.

Recently, Liu and Khan demonstrated that penthiopyrad formulated as Vertisan (DuPont), which belongs to the succinate dehydrogenase inhibitor fungicides, could be a good alternative fungicide for resistance management in sugar beet. Penthiopyrad can provide a similar level of protection as AZ when applied in-furrow or as soil drench. However, an application as a foliar spray did not result in sufficient disease control (Liu and Khan 2016b), which makes it unsuitable for usage in the E.U., where techniques like in-furrow spray application of fungicides are not allowed in sugar beet. For this reason, there is need for an alternative approach that minimizes the risk of resistance development and ensures a similar protection level as 
the application of $\mathrm{AZ}$ alone. On this account, two field trial series, with and without artificial inoculation, were carried out to evaluate the efficacy of a new fungicide mixture, containing the industry's standard AZ supplemented with the active ingredient difenoconazole (DFZ). This demethylation inhibiting fungicide, has been reported to possess good efficacy against $R$. solani (Dong et al. 2013; Meyer et al. 2006), which makes it a suitable active ingredient for the combination with AZ. In this study, the two fungicide treatments were evaluated for disease reduction and white sugar yield using sugar beet cultivars with and without Rhizoctonia resistance. Additionally, a newly developed real-time PCR assay based on large-scale soil samples (Schulze et al. 2016) was used to directly quantify the effects on the soil-borne $R$. solani inoculum.

\section{Materials and Methods}

Field trials. All trials were carried out in 2012, 2013, and 2014 in Lower Bavaria, Germany, near Platting in locations with natural $R$. solani infestation. Trials were conducted in a complete randomized block design with four replications. The plots consisted either of 12 or 6 rows, $6 \mathrm{~m}$ in length. Artificially inoculated trials were conducted in a total of six different environments (two per year) in 2012, 2013, and 2014, whereas trials without inoculation (relying on the natural infestation only) were carried out in four different environments (two per year) in 2013 and 2014. In inoculated trials, $80 \mathrm{~kg} / \mathrm{ha}$ barley kernels overgrown with $R$. solani AG 2-2 IIIB were applied according to Kluth et al. (2010). One day before sowing, the inoculum was evenly spread over the trial area at a 90 degree angle relative to the sowing direction and incorporated into the soil to a depth of $5 \mathrm{~cm}$ using a rotary harrow/drilling machine combination. In all trials, sugar beet seeds were placed every $6 \mathrm{~cm}$ and later singled to approximately 30 plants per row. General plant protection measures and agricultural operations were carried out according to regional guidelines to avoid impairment of the crop from other factors than $R$. solani.

Three different cultivars were evaluated under natural infestation as well as inoculation conditions. Two of the cultivars used are commercially available in Germany (ZR 1988 and ZR 1555) and are designated susceptible and less susceptible toward $R$. solani, respectively, according to the German Bundessortenamt (BSA 2015). Henceforth, these cultivars are termed susceptible and resistant. The third cultivar is derived from a Syngenta breeding program and represents a cultivar combining resistance characteristics with high yield abilities (unpublished data). Henceforth, this cultivar is referred to as intermediate. The fungicides tested were obtained from Syngenta Agro $\mathrm{GmbH}$. The first fungicide (Ortiva), containing 250 a.i./liter azoxystrobin, is registered in Germany for the control of Cercospora beticola in sugar beet. The second fungicide is a new mixture of the two active ingredients azoxystrobin (AZ) and difenoconazole (DFZ) in a concentration of $125 \mathrm{~g}$ a.i./liter each. The two fungicide treatments are hereafter referred to as AZ and AZ+DFZ, respectively.

The application was done twice during the growing season, at the six-leaf stage (BBCH16) and at 10\% canopy closure (BBCH31) using the nozzle IDKT 120-04 (Lechler, Metzingen) and an application dosage of 1 liter/ha in a volume of 400 liter/ha water. At the end of September, three inner rows of each plot, representing approximately 90 beets, were harvested by a sugar beet harvester and used for determination of disease severity and yield. After washing, all harvested beets were rated using a linear scale from 0 to $100 \%$ rotten beet surface in 5\% steps, ranging from small typical lesions to completely dead taproots. To account for roots with only small black pinpoint lesions, a substep of $2 \%$ rotten beet surface was added to this rating scheme. All harvested beets were processed into brei and sucrose concentration as well as content of melassogenic substances (potassium, sodium, and $\alpha$-amino-N) were determined to calculate the white sugar yield (WSY) (ICUMSA 2007; Märländer et al. 2003).

Soil sampling and DNA extraction. Sampling of soils was done for all trials (inoculated as well as naturally infested) carried out in two different environments (two trials $\times$ two environments) in 2014. To determine the initial inoculum, four randomly chosen plots of the inoculated as well as the noninoculated trial were sampled per location when the plants reached the four leaf-stage. To evaluate the effect of fungicide treatment and plant cultivar on the soil inoculum of $R$. solani over the growing season, additional soil samples from all plots were taken 2 weeks before harvest. The intermediate cultivar was excluded from this analysis. Sampling was carried out using soil samplers ("Göttinger Bohrstöcke") to excise soil cores of $10 \mathrm{~cm}$ depth and a diameter of $2 \mathrm{~cm}$. A total of 30 subsamples was taken within the rows designated for harvest in each plot and pooled. The samples were thoroughly mixed and $250 \mathrm{~g}$ were used for DNA extraction as previously described (Schulze et al. 2016). Quality of the extracted DNA was analyzed by electrophoresis and spectrophotometrically quantified (DS-11 Spectrophotometer, DeNovix, Wilmington, U.S.A.). The DNA solution was diluted to a final concentration of $25 \mathrm{ng} / \mu \mathrm{l}$ and subjected to real-time PCR analysis.

Real-time PCR analysis. The real-time PCR analysis was carried out following the procedure recently developed in our lab using an iTaq Universal SYBR Green approach (Bio-Rad Laboratories, Hercules, U.S.A.) and the targeted amplification of the internal transcribed spacer 1 (Schulze et al. 2016). For the preparation of a standard curve, genomic DNA was isolated from 7-day-old mycelium grown in potato dextrose broth (PDB) (Carl Roth GmbH, Karlsruhe, Germany) using the DNeasy Plant Mini Kit (Qiagen, Hilden, Germany) according to the manufacturer's instructions. Quality of the extracted DNA was analyzed by gel electrophoresis and quantified. A 10 -fold dilution series was produced, ranging from $100 \mathrm{ng} / \mu \mathrm{l}$ to $0.1 \mathrm{pg} / \mu \mathrm{l}$. All samples were analyzed in triplicate.

Determination of fungicide efficacy in vitro. The in vitro efficacy of the two fungicide treatments was evaluated following a modified protocol of Carling et al. (1990). Agar plugs, obtained from an actively growing fungal culture, were placed on potato dextrose agar (PDA) amended with fungicide at concentrations of $0,0.001,0.01$, $0.1,1,10$, and $100 \mathrm{mg}$ a.i./liter. Each concentration was tested in five repetitions. The plates were incubated for 4 days at $22^{\circ} \mathrm{C}$ in darkness. The radial growth was evaluated and used to calculate radial growth inhibition. $\mathrm{EC}_{50}$ values of the fungicides were determined according to Holmes and Eckert (1999).

Data analysis. The statistical analysis of the data was performed using SAS 9.4 software (SAS Institute, Cary, NC). Due to nonnormality, WSY and disease severity were ranked and nonparametric analysis of ranks was conducted using the procedure MIXED. Plant cultivar, type of fungicide treatment, and a combination of both were modeled as fixed factors, whereas the factors of year, location, block, and plot were considered as random effects. Separation of estimates between different subgroups was done by a procedure of Saxton (1998) where least square means, whose differences are not statistically significant, are clustered into letter groupings. Analysis of the effect of fungicide treatment and plant cultivar on the inoculum potential followed the analysis of disease severity and WSY, except that the fixed factor year was not included in the model, data were logtransformed and evaluated by a linear mixed model. To determine the differences between initial inoculum and inoculum at harvest, log-transformed data were analyzed using pairwise comparison in a linear mixed model. Regression analyses were conducted in Sigma Plot 13.0 (SYSTAT Software, Inc., Point Richmond, CA) and correlation coefficients were determined. All model assumptions were carefully checked and the significance level was set to $5 \%$.

\section{Results}

Fungicide efficacy in vitro. The analysis of the in vitro efficacy of $\mathrm{AZ}$ and the mixture of AZ + DFZ (50:50) against $R$. solani showed that the two fungicide treatments possess a similar $\mathrm{EC}_{50}$ of 72.6 and $79.4 \mathrm{mg}$ a.i./liter, respectively. Still, the correlation of the fungicide mixture followed a logistic regression $\left(R^{2}=0.933\right)$, showing a higher efficacy at lower concentrations (Fig. 1). In contrast, supplementation of solely AZ into the medium resulted in a linear growth inhibition $\left(\mathrm{R}^{2}=0.960\right)$.

Disease severity and white sugar yield under natural infection conditions. In trials with natural infestation, the overall infection level was low, indicated by an average disease severity of $6 \%$ in the untreated susceptible cultivar. Still, the analysis revealed a significant 
effect of the plant cultivar and a significant interaction of plant cultivar and fungicide treatment (Table 1). The susceptible cultivar (6\% disease severity for control) was significantly more diseased compared with the other cultivars ( 1 to $1.5 \%$ ) and furthermore, a significant effect of the fungicide treatment was observed in this cultivar (Fig. 2). The application of either $\mathrm{AZ}$ or $\mathrm{AZ}+\mathrm{DFZ}$ significantly decreased the average disease severity by $74 \%$ and $57 \%$, respectively, and increased the

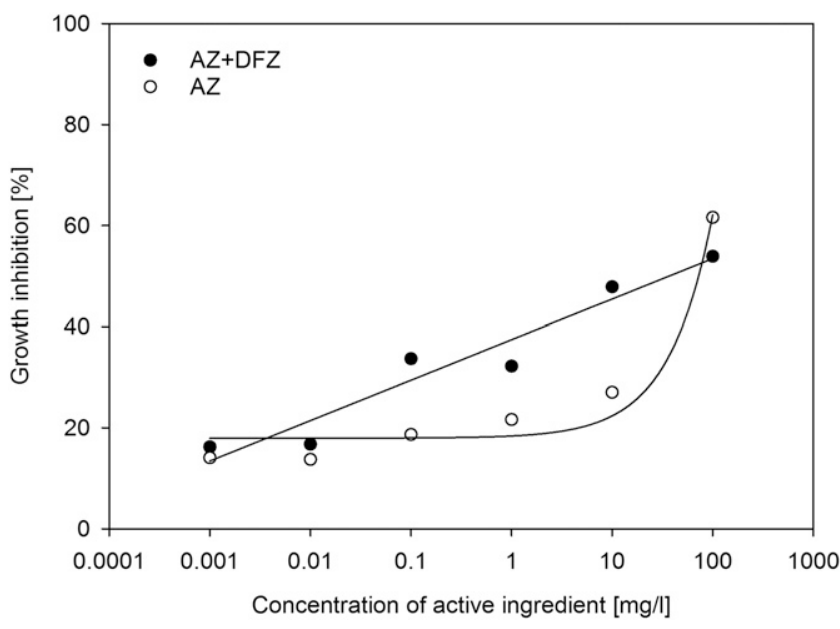

Fig 1. Correlation of average growth inhibition $(n=5)$ in vitro of Rhizoctonia solani AG 2-2 IIIB strain BBA69670 and concentration of active ingredient in cultural medium (potato dextrose agar). $A Z: y=17.942+0.442 x, R^{2}=0.960 ; A Z+D F Z: y=+$ $37.439+3.476 \ln (\mathrm{x}), \mathrm{R}^{2}=0.933$; azoxystrobin (AZ), difenoconazole (DFZ); analysis was conducted in Sigma Plot 13.0 (SYSTAT Software, Inc., Point Richmond, CA).

Table 1. Effects of fungicide treatment and plant cultivar on disease severity of Rhizoctonia solani and white sugar yield under natural infection conditions from four environments in Germany 2013 and $2014(n=16)^{\mathrm{a}}$

\begin{tabular}{llccc}
\hline & & Fungicide & Cultivar & Fungicide $\times$ cultivar \\
\hline Disease severity & F-value & 0.08 & 4.25 & 3.61 \\
& Pr $>$ F & 0.9269 & 0.0163 & 0.0408 \\
White sugar yield & F-value & 2.08 & 55.82 & 2.46 \\
& Pr $>$ F & 1.1292 & $<0.0001$ & 0.0491 \\
\hline
\end{tabular}

${ }^{a}$ Data were rank-transformed prior analysis with a mixed model (PROC MIXED; SAS Institute, Cary, NC). Year and location were considered as random effects.
WSY by $3 \%$ even at this low level of infection. Nevertheless, the WSY analysis demonstrated that without fungicide treatment, the yield obtained of the susceptible cultivar was $8.5 \%$ higher compared with the resistant cultivar. Without fungicide treatment, the intermediate cultivar showed an infestation level similar to the resistant cultivar and a WSY like the susceptible cultivar (Fig. 2). Under the given conditions, neither disease severity nor WSY was affected by the application of fungicides in this cultivar.

Disease severity and white sugar yield under artificial infestation conditions. Due to artificial inoculation, severe infection of the untreated sugar beet cultivars was observed in all tested locations resulting in a significant effect of fungicide treatment and cultivar on disease severity and WSY (Table 2). When not treated with fungicides, the susceptible cultivar displayed an average disease severity of $65 \%$, which was significantly higher compared with $21 \%$ and $30 \%$ for the resistant and intermediate cultivar, respectively (Fig. 3 ). Without fungicide treatment, the resistant cultivar showed the lowest disease severity of $21 \%$. The application of AZ + DFZ and AZ decreased the disease severity by 64 to $78 \%$ regardless of cultivar. The resistant and the intermediate cultivar did not differ significantly in their disease severity, regardless of fungicide treatment used. However, even though all cultivars were affected by Rhizoctonia root and crown rot, the susceptible cultivar displayed a significant higher disease severity for all treatments. The differences in disease severity were also reflected in the WSY obtained. All cultivars displayed a significant decrease in the WSY, when not treated with fungicides (Fig. 3). Without fungicide treatment, the resistant and the intermediate cultivar had a comparable WSY, whereas the WSY for the untreated susceptible cultivar was about $37 \%$ less. With the susceptible cultivar, the application of $\mathrm{AZ}$ resulted in an average WSY of $14.4 \mathrm{t} / \mathrm{ha}$ compared with $6.78 \mathrm{t} / \mathrm{ha}$ without fungicide treatment. When treated with fungicides, the average WSY of the resistant and the susceptible cultivar did not differ significantly, but the highest ranking treatments for WSY were the intermediate cultivar treated with fungicides.

Effect of plant cultivar and fungicide treatment on $\boldsymbol{R}$. solani DNA content in the soil. The initial DNA concentration in the field trial areas was determined by sampling four randomly selected plots per inoculation level at each site (four samples per four environments $=16$ samples total) before fungicide application. Without inoculation, the average $R$. solani DNA concentration was $14.2 \pm 8.6 \mathrm{pg} / \mathrm{g}$ soil and the inoculation increased this value to $132 \pm 292 \mathrm{pg} / \mathrm{g}$. At harvest, the concentration of $R$. solani DNA in the soil was again evaluated and the effects of the cultivar and the fungicide treatment were compared. Without inoculation, a few patches of Rhizoctonia root and crown rot had developed in the plots, mainly in the untreated
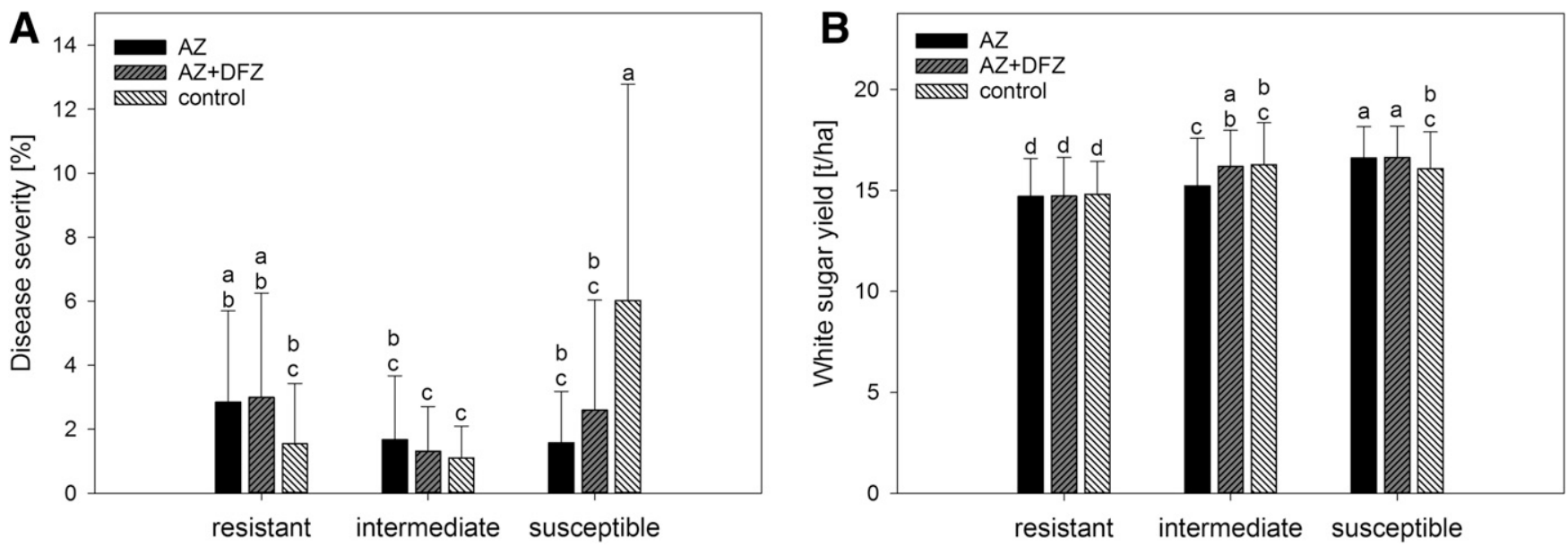

Fig. 2. Average disease severity of Rhizoctonia root and crown rot (R. solani) $(\mathbf{A})$ and white sugar yield $(\mathbf{B})$ of three sugar beet cultivars treated with different fungicides applied in BBCH16 and BBCH31 under natural infection conditions in Germany 2013 and 2014. Values represent means of 16 replicates from four environments (two per year) with error bars indicating the standard deviation. Bars with common letters do not differ significantly from each other according to the analysis with PROC MIXED and the least significant difference mean separation test $(P<0.05)$. Statistical analysis is based on ranked data but untransformed data are presented in the figure. $A Z=a z o x y s t r o b i n ~(250 \mathrm{~g}$ a.i./liter applied at 1 liter/ha); DFZ = difenoconazole (125 g a.i./liter applied at 1 liter/ha). 
susceptible cultivar. This inhomogeneous distribution is also reflected in the $R$. solani DNA concentration in the soil and led to high variation between plots of the same treatment, most pronounced in the plots of the untreated susceptible cultivar, where they ranged between 1.4 and 21,232.4 pg/g soil. Without inoculation, no statistical significant differences between the treatments (fungicide and cultivar) were observed at harvest (Table 3). Still, the comparison of $R$. solani DNA concentration at the beginning of the growing season with the inoculum density at harvest showed a significant reduction of the soil-borne inoculum when either the resistant cultivar was treated with $\mathrm{AZ}+\mathrm{DFZ}$ or the susceptible cultivar was treated with AZ under natural infestation (Table 4).

Artificial inoculation led to a higher disease pressure and a more homogenous disease development. This resulted in a significant effect of the plant cultivar as well as of the fungicide treatment on the $R$. solani inoculum in the soil in the susceptible cultivar (Table 3). Both fungicide treatments significantly reduced the $R$. solan $i$ concentration in the soil (Fig. 4). Cultivation of the untreated resistant cultivar or the combination of susceptible cultivar with AZ treatment led to an increase by a factor of 10 compared with the initial inoculum. However, this difference was not statistically significant. In contrast, the combination of susceptible cultivar and AZ + DFZ treatment resulted in an inoculum increase by a factor of 20 . Without chemical treatment of the susceptible cultivar, the $R$. solani DNA concentration in the soil raised to a level 200 times higher than the initial inoculum. Both differences were statistically significant.

Generally, a lower $R$. solani DNA content was found in plots of the resistant cultivar, compared with plots where the susceptible cultivar was grown. At harvest, the $R$. solani DNA concentration was increased in all plots of the susceptible cultivar compared with the initial inoculum. However, only in plots that were either untreated or treated with $\mathrm{AZ}+\mathrm{DFZ}$ were the differences statistically significant.

Table 2. Effects of fungicide treatment and plant cultivar on disease severity of Rhizoctonia solani and white sugar yield under inoculation conditions from six environments in Germany 2012, 2013, and $2014(n=24)^{\mathrm{a}}$

\begin{tabular}{llllc}
\hline & & Fungicide & Cultivar & Fungicide $\times$ cultivar \\
\hline Disease severity & F-value & 97.25 & 58.40 & 2.07 \\
& Pr $>$ F & $<0.0001$ & $<0.0001$ & 0.0860 \\
White sugar yield & F-value & 92.03 & 11.58 & 10.18 \\
& Pr $>$ F & $<0.0001$ & $<0.0001$ & $<0.0001$ \\
\hline
\end{tabular}

a Data were rank-transformed prior analysis with a mixed model (PROC MIXED; SAS Institute, Cary, NC). Year and location were considered as random effects.
Further analysis demonstrated a significant linear correlation between the disease severity and the $R$. solani DNA concentration in the soil $\left(\mathrm{R}^{2}=0.763\right)$ (Fig. 5).

\section{Discussion}

This study compares the efficacy of two fungicide treatments in vitro and in vivo using natural infection conditions as well as inoculation in the field. The results demonstrate that the fungicide treatment containing the two active ingredients AZ and DFZ displayed a similar fungicide efficacy as the "industry standard" AZ as sole active ingredient in vitro and efficiently controlled Rhizoctonia root and crown rot in sugar beet, decreasing disease severity, preventing losses in WSY, and reducing the soil-borne inoculum.

In naturally infested fields, Rhizoctonia root and crown rot appears in patches that vary in size and expand during the growing season, leading to an inhomogeneous disease incidence (Anees et al. 2010). In most cases, this characteristic prevents the identification of statistical significant effects. In general, the analysis of naturally infested field trials is further complicated by the fact that the occurrence and severity of soil-borne diseases like Rhizoctonia root and crown rot is unpredictable, since even in fields with a severe disease history, the visible symptoms of the pathogen are absent in some years (Anees et al. 2010; Kirk et al. 2008). Also in this trial series, patches of Rhizoctonia root and crown rot developed in the trials with natural infestation and led to high standard deviations between repetitions. Still, the trials with natural infestation demonstrated that the susceptible cultivar was significantly more diseased compared with the resistant or the intermediate cultivar unless it was treated with fungicides. To our knowledge, this is the first statistical verification of the fungicide efficacy regarding the control of $R$. solani in sugar beet under natural infections conditions using data from several environments and years in Europe.

Furthermore, the study underlines the difficulty of the farmers to choose the right cultivar, since even though the susceptible cultivar was significantly more diseased when not treated with fungicides, the WSY was still about $8 \%$ higher than in the resistant cultivar. This indicates that the cultivation of resistant cultivars is only economically reasonable when the disease pressure is very high, which is not predictable to date. However, from a phytopathological point of view, the use of susceptible cultivars cannot be recommended, since this has been shown to increase the inoculum potential and promotes further disease development (Hwang et al. 2012; Naiki and Ui 1977; Schulze et al. 2016). A similar trend was also observed in this study, where the average $R$. solani DNA concentration in soil had increased from 14.02 to $2,859.39 \mathrm{pg} / \mathrm{g}$ after the cultivation of the susceptible cultivar without chemical treatment.
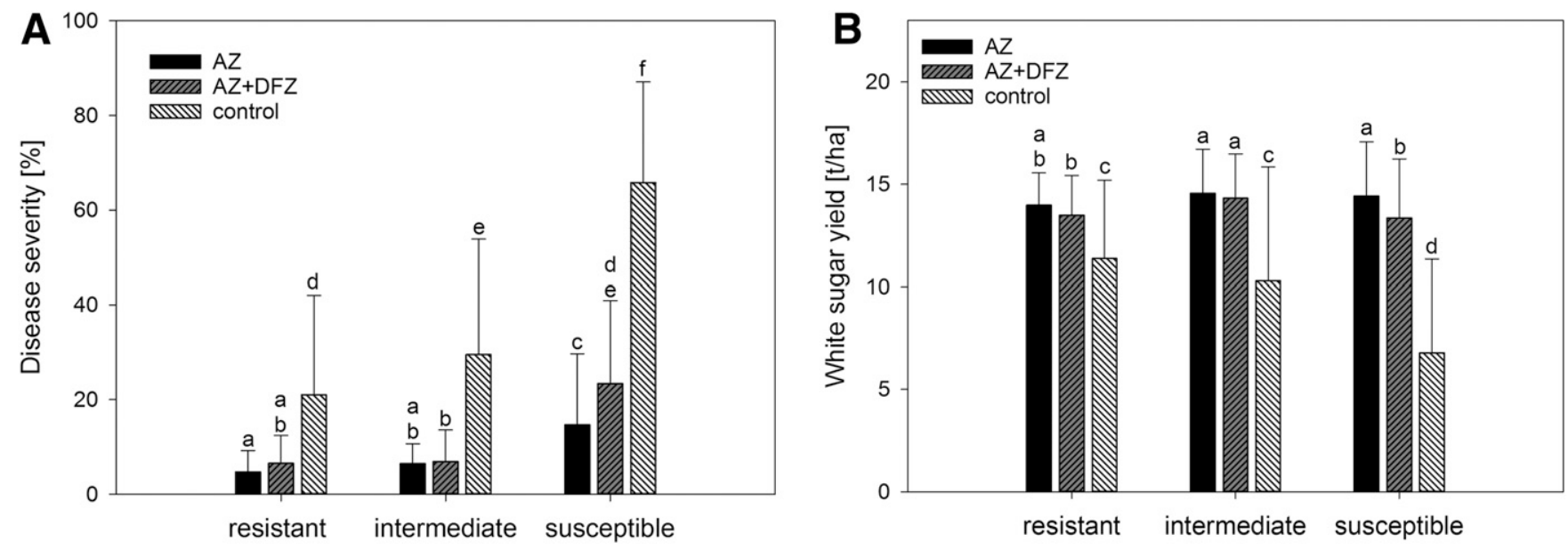

Fig. 3. Average disease severity of Rhizoctonia root and crown rot (R. solani) $(\mathbf{A})$ and white sugar yield $(\mathbf{B})$ of three sugar beet cultivars treated with different fungicides applied in BBCH16 and BBCH31 under inoculation conditions in Germany 2012, 2013, and 2014. Values represent mean of 24 replicates from six environments (two per year) with error bars indicating the standard deviation. Bars with common letters do not differ significantly from each other according to the analysis with PROC MIXED and the least significant difference mean separation test $(P<0.05)$. Statistical analysis is based on ranked data but untransformed data are presented in the figure. $A Z=a z o x y s t r o b i n ~(250 \mathrm{~g}$ a.i./liter applied at 1 liter/ha); DFZ = difenoconazole (125 g a.i./liter applied at 1 liter/ha). 
The artificial inoculation resulted in a more homogenous distribution of Rhizoctonia root and crown rot and increased the disease pressure to a very high level, as indicated by an average of $65 \%$ disease severity in the untreated susceptible cultivar. Even though yield loss of $60 \%$ due to $R$. solani have been reported in sugar beet (Allen et al. 1985 ), the created infestation level exceeds $R$. solani infestation usually observed in the field, which range between 0 and 50\% (Büttner et al. 2002; Whitney and Duffus 1986). This has to be kept in mind when analyzing these data. However, even at this high disease pressure, the fungicide treatment decreased the disease severity and prevented WSY losses in all cultivars. The application of each of the fungicide treatments resulted in a similar level of protection, except in the susceptible cultivar. Without the fungicide treatment, the susceptible cultivar was significantly more diseased than the resistant one and in contrast to the slight infestation in the trials without artificial inoculation, this resulted in severe yield loss.

Table 3. Effects of fungicide treatment and plant cultivar on Rhizoctonia solani-DNA concentration in the soil under inoculation as well as natural infestation conditions from two locations in Germany $2014(n=8)^{\mathrm{a}}$

\begin{tabular}{llccc}
\hline & & Fungicide & Cultivar & Fungicide $\times$ cultivar \\
\hline Naturally infested & F-value & 0.03 & 0.79 & 2.71 \\
& $\mathrm{Pr}>\mathrm{F}$ & 0.9736 & 0.3780 & 0.0785 \\
Inoculated & $\mathrm{F}$-value & 8.92 & 30.17 & 0.94 \\
& $\mathrm{Pr}>\mathrm{F}$ & 0.0044 & 0.0002 & 0.4176 \\
\hline
\end{tabular}

${ }^{a}$ Data were log-transformed prior analysis with a mixed model (PROC MIXED; SAS Institute, Cary, NC). Year and location were considered as random effects.

Table 4. Comparison of average Rhizoctonia solani DNA concentration in the soil (pg/g) at the beginning of the growing season (initial inoculum) and at harvest in German sugar beet fields $2014(n=8)^{\mathrm{a}}$

\begin{tabular}{llcc}
\hline & & Naturally infested & Inoculated \\
\hline Resistant cultivar & AZ & 11.65 & 153.91 \\
& AZ + DFZ & $6.10^{*}$ & 35.79 \\
& control & 25.07 & $1,703.68$ \\
Susceptible cultivar & AZ & $4.18^{*}$ & $1,307.75$ \\
& AZ + DFZ & $1,026.38$ & $2,996.65^{*}$ \\
& control & $2,859.39$ & $26,974.46^{*}$ \\
Initial inoculum & & 14.02 & 132 \\
\hline
\end{tabular}

${ }^{a}$ Data were log-transformed prior analysis with a mixed model (PROC MIXED; SAS Institute, Cary, NC); * indicates significant differences $(P \leq 0.05)$ based on pairwise comparisons.
The highest WSY was obtained when the intermediate cultivar was either treated with AZ or AZ + DFZ. When the fungicide treatments were applied, the resistant and the susceptible cultivar yielded a similar WSY. Nevertheless, at harvest, the $R$. solani inoculum in the soil was significantly increased in the plots of the susceptible cultivar compared with the resistant one. Even though the fungicide application significantly reduced the concentration of $R$. solani DNA in the soil, the results indicate that only the combination of resistant cultivar and chemical treatment resulted in a decrease or steady level of the $R$. solani inoculum in the soil compared with the initial concentration. This finding is very interesting since the number of reports regarding the long-term effects of fungicide application on fungal pathogens, evaluated by real-time PCR, is very limited. The few available reports demonstrate that fungicide application can persistently reduce the fungal inoculum, which has been documented for plant surfaces as well as soils and is in accordance with the findings of this analysis (Diguta et al. 2010; Marburger et al. 2015). Still, the data presented here were retrieved only from two locations in one year and no further analysis of the long-term fate of this inoculum has been performed yet. Schulze et al. (2016) demonstrated that the inoculum potential of $R$. solani in sugar beet is significantly reduced by the cultivation of nonhosts, but more detailed analysis about the dynamics of soil-borne inoculum and the effect on disease severity are needed.

To date, the applied method for direct inoculum quantification via real-time PCR based on DNA extractions of soil samples, taking into account the heterogeneous spatial distribution of $R$. solani in naturally infested fields, is the best known approach to study the dynamics of soil-borne inoculum and different factors like plant resistance and fungicide application affecting it. In contrast to the rating of the disease severity, which gives only an indication of the real pathogen concentration and is prone to assessment errors (Bock et al. 2010), the quantification via $\mathrm{QPCR}$ gives standardized and reproducible results. Other quantification methods that rely on the isolation of soilborne pathogens, e.g., baiting techniques, have been proven difficult, especially when the targeted fungus is present in low concentration or the emergence of dormant propagules like sclerotia is necessary and result in a fitness disadvantage compared with the secondary microflora present in soil samples (Sanzani et al. 2014 and references therein).

In this study, the rated disease severity and the quantified inoculum showed a strong correlation, underlining the reliability of the quantification method used. Whereas a correlation between disease severity and fungal DNA concentration in the plant tissue is well established (Sanzani et al. 2014 and references therein), reports about a significant correlation between disease severity and pathogen
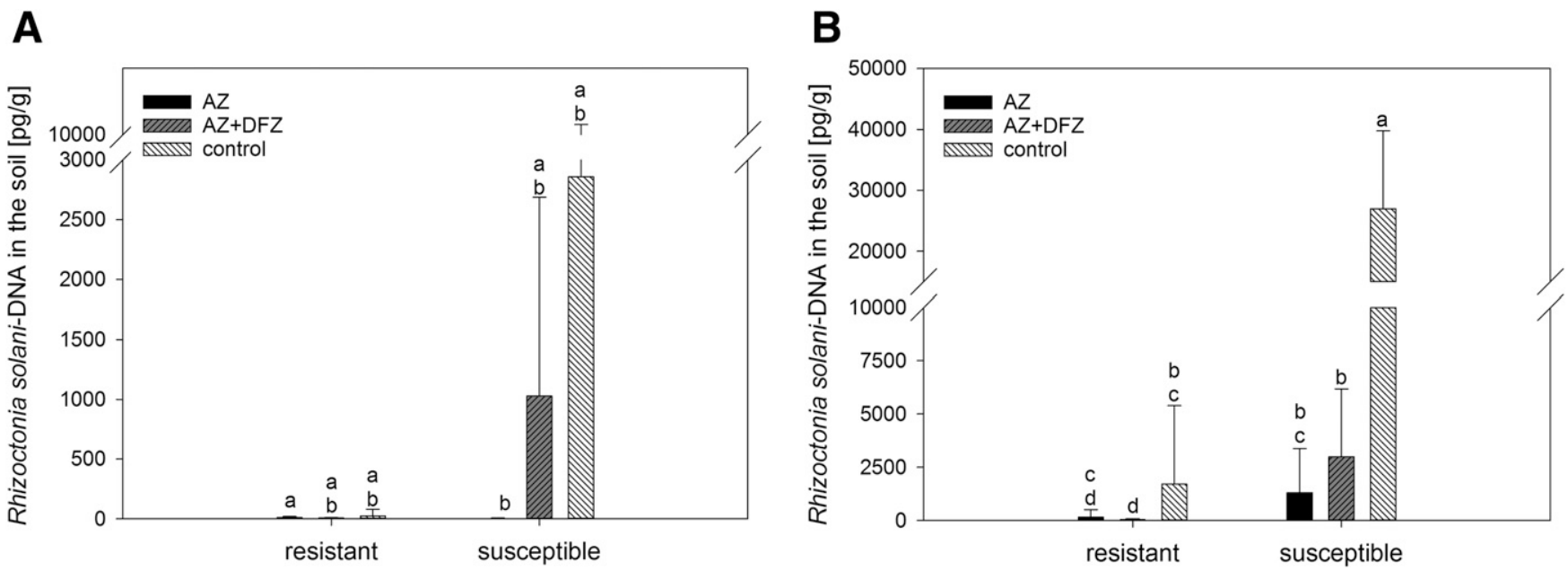

Fig. 4. Average Rhizoctonia solani DNA concentration in the soil $(0$ to $10 \mathrm{~cm})$ of plots cultivated with two sugar beet cultivars treated with different fungicides applied in BBCH16 and BBCH31 under natural infection (A) and inoculation conditions (B) in Germany 2014. Values represent mean of 16 replicates from four environments with error bars indicating the standard deviation. Bars with common letters do not differ significantly from each other according to the analysis with PROC MIXED and the least significant difference mean separation test $(P<0.05)$. Statistical analysis is based on log-transformed data but untransformed data are presented in the figure. $A Z=$ azoxystrobin $(250 \mathrm{~g}$ a.i./liter applied at 1 liter/ha); DFZ = difenoconazole (125 g a.i./liter applied at 1 liter/ha). 
inoculum in the soil are very rare (Marburger et al. 2015). Schulze et al. (2016) did not find a correlation between inoculum density and disease severity, which is probably due to the low infestation level observed in their trials. In contrast, Naiki and Ui (1977) demonstrated that the number of sclerotia formed by $R$. solani is significantly correlated with the amount of diseased beet surface. Based on this and the results of this study, it can be assumed that the formation of the soil-borne inoculum depends on the amount of diseased beet surface only and is not affected by the sugar beet cultivar. However, only two cultivars were tested in this study and the evaluation of more cultivars is needed for further validation of this hypothesis.

The utility of the assay used for inoculum quantification, demonstrated by the presented results, suggest to extend its usage for the evaluation of the dynamics of the inoculum potential over years. Even though many factors like environmental conduciveness are essential for disease development, determination of the inoculum in the soil via qPCR could allow the identification of soil inoculum threshold levels necessary for disease development in the future (Sanzani et al. 2014; Windels and Brantner 2005). This might also allow the reliable identification of high-risk fields, which renders the possibility of targeted control measures by, e.g., fungicide application (Sanzani et al. 2014).

In conclusion, the used real-time PCR assay was a valuable tool to study the effect of chemical treatment and plant cultivar on the soilborne inoculum of $R$. solani. Although the negative effects on yield were limited at low disease pressure, the analysis clearly demonstrated that the cultivation of susceptible cultivars led to a strong increase of the fungal biomass in the soil in naturally infested fields. The application of fungicides reduced the concentration of soil-borne inoculum in inoculated fields. However, despite the fact that the WSY of the susceptible and the resistant cultivar were similar when treated with fungicides, the propagation of soil-borne inoculum due to the cultivation of the susceptible cultivar was significantly higher.

The aim of soil-borne pathogen control is to keep the inoculum level in the soil low, since it is mostly not possible to achieve a complete exclusion (Sanzani et al. 2014). This study indicates that this cannot be achieved by the combination of a chemical treatment and a susceptible cultivar. Furthermore, the results suggest that also the resistant cultivar propagates the soil-borne inoculum of $R$. solani in sugar beet when the disease pressure is very high. For this reason, only the combination of plant resistance and fungicide treatment will be a suitable measure to prevent an accumulation of inoculum in years with conducive conditions at infested locations. In this study, both tested fungicide treatments displayed a similar efficacy, suggesting that a fungicide treatment containing $\mathrm{AZ}+\mathrm{DFZ}$ is an

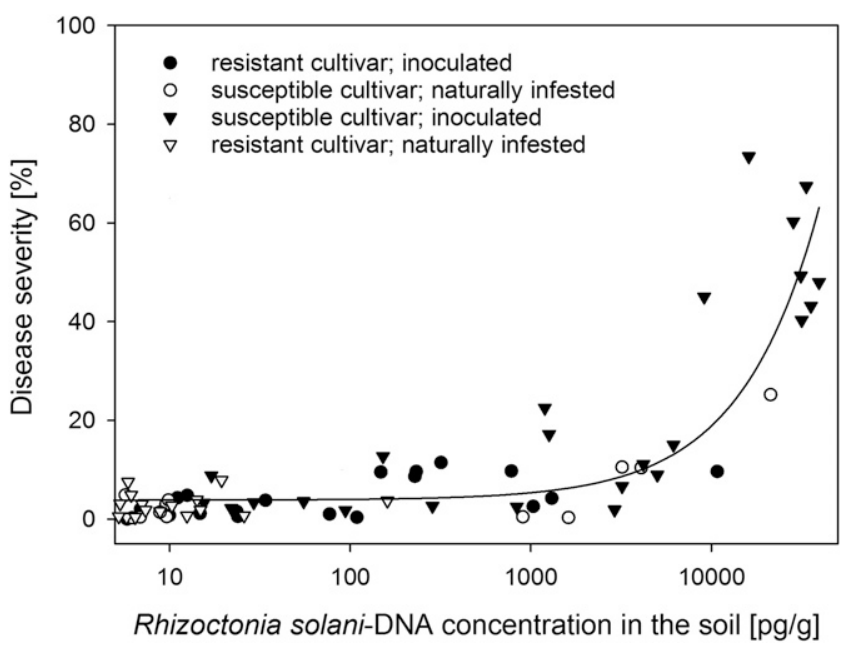

Fig. 5. Correlation of percentage of disease severity and Rhizoctonia solani DNA concentration in the soil at harvest in Germany 2014; $y=0.002 x+3.839, R^{2}=$ $0.763 ; n=48$. Analysis was conducted in Sigma Plot 13.0 (SYSTAT Software, Inc., Point Richmond, CA). appropriate measure to control $R$. solani in sugar beet and reduces the risk of fungicide resistance development at the same time.

\section{Acknowledgments}

We thank the technical staff of the Syngenta Agro GmbH, the Institute of Sugar Beet Research, and in particular Tino Voltmann for their active cooperation; the collaborating farmers for their support, David Ellenberger for statistical advice, and the Syngenta Agro GmbH for financial support.

\section{Literature Cited}

Allen, M. F., Boosalis, M. G., Kerr, E. D., Muldoon, A. E., and Larsen, H. J. 1985 Population dynamics of sugar beets, Rhizoctonia solani, and Laetisaria arvalis: Responses of a host, plant pathogen, and hyperparasite to perturbation in the field. Appl. Environ. Microbiol. 50:1123-1127.

Anderson, N. A. 1982. The genetics and pathology of Rhizoctonia solani. Annu. Rev. Phytopathol. 20:329-347.

Anees, M., Edel-Hermann, V., and Steinberg, C. 2010. Build up of patches caused by Rhizoctonia solani. Soil Biol. Biochem. 42:1661-1672.

Arakawa, M., and Inagaki, K. 2014. Molecular markers for genotyping anastomosis groups and understanding the population biology of Rhizoctonia species. J. Gen. Plant Pathol. 80:401-407.

Barnett, K. A., Sprague, C. L., Kirk, W. W., and Hanson, L. E. 2011. Lack of interaction between glyphosate and fungicide treatments on Rhizoctonia crown and root rot in glyphosate-resistant sugarbeet. J. Sugar Beet Res. 48:1-17.

Bartlett, D. W., Clough, J. M., Godwin, J. R., Hall, A. A., Hamer, M., and ParrDobrzanski, B. 2002. The strobilurin fungicides. Pest Manag. Sci. 58:649-662

Blazier, S. R., and Conway, K. E. 2004. Characterization of Rhizoctonia solani isolates associated with patch diseases on turfgrass. Proc. Okla. Acad. Sci. $84: 41-51$

Bock, C. H., Poole, G. H., Parker, P. E., and Gottwald, T. R. 2010. Plant disease severity estimated visually, by digital photography and image analysis, and by hyperspectral imaging. Crit. Rev. Plant Sci. 29:59-107.

Bolton, M. D., Panella, L., Campbell, L., and Khan, M. F. 2010. Temperature, moisture, and fungicide effects in managing Rhizoctonia root and crown rot of sugar beet. Phytopathology 100:689-697.

Brent, K. J., and Hollomon, D. W. 2007. Fungicide resistance in crop pathogens: How can it be managed? FRAC Monogr. 1, 2nd ed. GIFAP, Brussels.

BSA. 2015. Beschreibende Sortenliste Getreide, Mais, Ölfrüchte, Leguminosen, Hackfrüchte. Bundessortenamt, Deutscher landwirtschaftlicher Verlag, Hannover, Germany.

Buddemeyer, J., and Märländer, B. 2005. Genotypic reaction of sugar beet to Rhizoctonia solani root and crown rot - susceptibility, yield and quality at different levels of infestation. J. Plant Dis. Prot. 112:105-117.

Buhre, C., Kluth, C., Bürcky, K., Märländer, B., and Varrelmann, M. 2009. Integrated control of root and crown rot in sugar beet: Combined effects of cultivar, crop rotation, and soil tillage. Plant Dis. 93:155-161.

Büttner, G., Führer Ithurrart, M. E., and Buddemeyer, J. 2002. Späte Rübenfäule Rhizoctonia solani - Verbreitung, wirtschaftliche Bedeutung und integrierte Bekämpfungskonzepte. Sugar Indus. 52:707-717.

Carling, D. E., Baird, R. E., Gitaitis, R. D., Brainard, K. A., and Kuninaga, S. 2002 Characterization of AG-13, a newly reported anastomosis group of Rhizoctonia solani. Phytopathology 92:893-899.

Carling, D. E., Helm, D. J., and Leiner, R. H. 1990. In vitro sensitivity of Rhizoctonia solani and other multinucleate and binucleate Rhizoctonia to selected fungicides. Plant Dis. 74:860-863.

Diguta, C. F., Rousseaux, S., Weidmann, S., Bretin, N., Vincent, B., Guilloux-Benatier M., and Alexandre, H. 2010. Development of a qPCR assay for specific quantification of Botrytis cinerea on grapes. FEMS Microbiol. Lett. 313:81-87.

Djébali, N., Elkahoui, S., Taamalli, W., Hessini, K., Tarhouni, B., and Mrabet, M. 2014. Tunisian Rhizoctonia solani AG3 strains affect potato shoot macronutrients content, infect faba bean plants and show in vitro resistance to azoxystrobin. Australas. Plant Pathol. 43:347-358.

Dong, F., Li, J., Chankvetadze, B., Cheng, Y., Xu, J., Liu, X., Li, Y., Chen, X., Bertucci, C., Tedesco, D., Zanasi, R., and Zheng, Y. 2013. Chiral triazole fungicide difenoconazole: Absolute stereochemistry, stereoselective bioactivity, aquatic toxicity, and environmental behavior in vegetables and soil. Environ. Sci. Technol. 47:3386-3394.

Fernández-Ortuño, D., Torés, J. A., De Vicente, A., and Pérez-García, A. 2010. Mechanisms of resistance to QoI fungicides in phytopathogenic fungi. Int. Microbiol. 11:1-9.

Garcia, A. J., Büttner, G., Guitierrez, H., Heijbroek, W., Ioannides, P., Nihlgaard, M., Richard Molard, M., Panella, L., Rossi, V., Rösner, H., Schneider, J. H. M., and Wouters, A. 2001. Integrated control of Rhizoctonia root rot - first results of an I.I. R.B. trial series. Pages 397-400 in: Proceedings of the 64th IIRB Congress.

Holmes, G. J., and Eckert, J. W. 1999. Sensitivity of Penicillium digitatum and P. italicum to postharvest citrus fungicides in California. Phytopathology 89:716-721.

Hwang, S. F., Ahmed, H. U., Zhou, Q., Strelkov, S. E., Gossen, B. D., Peng, G., and Turnbull, G. D. 2012. Assessment of the impact of resistant and susceptible canola on Plasmodiophora brassicae inoculum potential. Plant Pathol. 61:945-952.

ICUMSA. 2007. ICUMSA Methods Book 2007. International Commission for Uniform Methods of Sugar Analysis, Verlag Dr. Albert Bartens KG, Berlin. 
Kiewnick, S., Jacobsen, B. J., Braun-Kiewnick, A., Eckhoff, J. L., and Bergman, J. W. 2001. Integrated control of Rhizoctonia crown and root rot of sugar beet with fungicides and antagonistic bacteria. Plant Dis. 85:718-722.

Kirk, W. W., Wharton, P. S., Schafer, R. L., Tumbalam, P., Poindexter, S., Guza, C., Fogg, R., Schlatter, T., Stewart, J., Hubbell, L., and Ruppal, D. 2008. Optimizing fungicide timing for the control of Rhizoctonia crown and root rot of sugar beet using soil temperature and plant growth stages. Plant Dis. 92:1091-1098.

Kluth, C., Buhre, C., and Varrelmann, M. 2010. Susceptibility of intercrops to infection with Rhizoctonia solani AG 2-2 IIIB and influence on subsequently cultivated sugar beet. Plant Pathol. 59:683-692.

Liu, Y., and Khan, M. F. 2016a. Utility of fungicides for controlling Rhizoctonia solani on sugar beet. J. Crop Prot. 5:33-38.

Liu, Y., and Khan, M. F. 2016b. Penthiopyrad applied in close proximity to Rhizoctonia solani provided effective disease control in sugar beet. Crop Prot. 85:33-37.

Marburger, D. A., Venkateshwaran, M., Conley, S. P., Esker, P. D., Lauer, J. G., and Ané, J. M. 2015. Crop rotation and management effect on Fusarium spp. populations. Crop Sci. 55:365-376.

Märländer, B., Hoffmann, C., Koch, H. J., Ladewig, E., Merkes, R., Petersen, J., and Stockfisch, N. 2003. Environmental situation and yield performance of the sugar beet crop in Germany: Heading for sustainable development. J. Agron. Crop Sci. 189:201-226.

Meyer, M. C., Bueno, C. J., De Souza, N. L., and Yorinori, J. T. 2006. Effect of doses of fungicides and plant resistance activators on the control of Rhizoctonia foliar blight of soybean, and on Rhizoctonia solani AG1-IA in vitro development. Crop Prot. 25:848-854.

Naiki, T., and Ui, T. 1977. Population and distribution of sclerotia of Rhizoctonia solani Kühn in sugar beet field soil. Soil Biol. Biochem. 9:377-381.

Olaya, G., Buitrago, C., Pearsaul, D., Sierotzki, H., and Tally, A. 2012. Detection of resistance to QoI fungicides in Rhizoctonia solani isolates from rice. Phytopathology 102:S4.
Panella, L., and Ruppel, E. G. 1996. Availability of germplasm for resistance against Rhizoctonia spp. Pages 515-527 in: Rhizoctonia species: Taxonomy, Molecular Biology, Ecology, Pathology and Disease Control. B. Sneh, S Jabaji-Hare, S. Neate, and G. Dijat, eds. Kluwer Academic Publishers, Dordrecht, The Netherlands.

Rush, C. M., and Winter, S. R. 1990. Influence of previous crops on Rhizoctonia root and crown rot of sugar beet. Plant Dis. 74:421-425.

Sanzani, S. M., Li Destri Nicosia, M. G., Faedda, R., Cacciola, S. O., and Schena, L. 2014. Use of quantitative PCR detection methods to study biocontrol agents and phytopathogenic fungi and oomycetes in environmental samples. J. Phytopathol. 162:1-13.

Saxton, A. M. 1998. A macro for converting mean separation output to letter groupings in Proc Mixed. Pages 1243-1246 in Proc. 23rd SAS Users Group Intl. Nashville, TN. SAS Institute, Cary. NC.

Schulze, S., Koch, H. J., Märländer, B., and Varrelmann, M. 2016. Effect of sugar beet variety and non-host plant on Rhizoctonia solani AG2-2IIIB soil inoculum potential measured in soil DNA extracts. Phytopathology 106:1047-1054.

Strausbaugh, C. A., Eujayl, I. A., Panella, L. W., and Hanson, L. E. 2011. Virulence, distribution and diversity of Rhizoctonia solani from sugar beet in Idaho and Oregon. Can. J. Plant Pathol. 33:210-226.

Stump, W. L., Franc, G. D., Harveson, R. M., and Wilson, R. G. 2004. Strobilurin fungicide timing for Rhizoctonia root and crown rot suppression in sugarbeet. J. Sugar Beet Res. 41:17-38.

Stump, W. L., Franc, G. D., Miller, S. D., and Wilson, R. G. 2002. Azoxystrobin and post emergence herbicide combinations for Rhizoctonia and weed management in sugarbeet. J. Sugar Beet Res. 39:37-58.

Whitney, E. D., and Duffus, J. E. 1986. Compendium of beet diseases and insects. American Phytopathological Society, St. Paul, MN.

Windels, C. E., and Brantner, J. R. 2005. Early-season application of azoxystrobin to sugarbeet for control of Rhizoctonia solani AG 4 and AG 2-2. J. Sugar Beet Res. 42:1-16. 